\title{
DERANGED SERUM LIPID LEVELS IN WOMEN
}

\section{WITH PREECLAMPSIA.}

\author{
DR. AYESHA ASLAM, MBBS \\ Nishtar Hospital Multan, Pakistan. \\ DR. ARUBA KHALID, MBBS \\ Nishtar Hospital Multan, Pakistan. \\ DR. MUHAMMAD AHMED, MBBS \\ Nishtar Hospital Multan, Pakistan.
}

\begin{abstract}
;
Background; Preeclampsia (PE), as a risky pregnancy, is a systemic disease characterized by hypertension, proteinuria and edema, which are thought to be the result of diffuse endothelial activation and dysfunction. About $5 \%$ of all pregnant women have PE during the second half of gestation that can cause maternal death throughout the world and is accompanied by substantial perinatal morbidity and mortality. Objective; To determine the frequency of dyslipidemia in women with preeclampsia at a tertiary care hospital. Material and Methods; A total of 135 women with preeclampsia (Both primigravida and multigravida) aged $20-40$ years were included in our study. Patients with twin pregnancy, taking lipid lowering therapy were excluded from our study. Detailed history and physical examination was conducted. Five ml venous blood sample was drawn and sent to central pathology laboratory of Nishtar Hospital, Multan for serum lipid profile estimation. Data was analyzed by using SPSS Version 20. Results; Mean gestational age of our study cases was $33.24 \pm 2.77$ weeks. Mean age of our study cases was $29.61 \pm 3.54$ years. Family history was positive in $41(30.4 \%)$ of our study cases. Diabetes was present in $25(18.5 \%)$ of our study cases. Mean parity was $2.59 \pm 1.72$ and $77(57.0 \%)$ had parity up to 3 . Mean body mass index of our study cases was $25.85 \pm 2.54 \mathrm{~kg} / \mathrm{m}^{2}$ and obesity was present in $31(23.0 \%)$ of our study cases. Of these 135 study cases, $104(77.0 \%)$ were illiterate while $31(23.0 \%)$ were literate. Of these 135 study cases, dyslipidemia was present in 73 (54.1\%). Mean Serum Cholesterol level was $223.45 \pm 47.21 \mathrm{mg} / \mathrm{dl}$ and it was deranged in 71 (52.59\%), mean serum LDL level was $147.15 \pm 31.25 \mathrm{mg} / \mathrm{dl}$ and it was deranged in 72 $(53.33 \%)$, mean serum triglyceride level was $154.21 \pm 15.29 \mathrm{mg} / \mathrm{dl}$ and it was deranged in $70(51.85 \%)$ of our study cases and mean HDL level was $52.42 \pm 8.53 \mathrm{mg} / \mathrm{dl}$ while it was deranged in 14 (10.37\%). Conclusion; Very high frequency of dyslipidemia was noted in our study in pre-eclamptic women. Dyslipidemia was significantly associated with gestational age, parity and diabetes. All the preeclamptic women should be screened for serum lipid levels and be managed accordingly to avoid future fetomaternal adverse outcomes.
\end{abstract}

Keywords; Preeclampsia, dyslipidemia, Frequency.

DOI: $10.7176 / \mathrm{JMPB} / 52-08$

\section{INTRODUCTION;}

Pre-eclampsia is common medical complication of pregnancy. It is a multisystem disorder characterized by systolic blood pressure above $140 \mathrm{mmHg}$ and/or diastolic pressure $>90 \mathrm{mmHg}$ measured at least two times with 4 hours interval and proteinuria $\geq 300 \mathrm{mg} / \mathrm{day}$, after 20 weeks of gestation ${ }^{1}$. It involves $2-8 \%$ of pregnancies and it is leading cause of maternal and neonatal mortality and morbidity ${ }^{2,3}$. In addition, women with a history of preeclampsia are at an increased risk for cardiovascular disease later in life. Risk factors for development of preeclamsia include extremes of maternal age ( $>35$ years or $<15$ years), obesity, diabetes mellitus, history of renal disease or chronic hypertension, multiple gestation, and African American race ${ }^{4,5}$. However various factors are 
implicated in the pathogenesis of preeclampsia including genetic, immune, vascular and oxidative stress, yet its etiology remains unclear, and little is still known about the pathogenesis of preeclampsia, making its prevention an ongoing challenge ${ }^{5}$.

Endothelial dysfunction is the most acceptable theory for etiology of preeclampsia. In this disorder due to deposition of fibrin and platelet and accumulation of lipid-laden microphages within vascular bed, placental perfusion is reduced. These findings have lead to the hypothesis that disorders of lipid metabolism might be a major cause of endothelial dysfunction ${ }^{6}$. Women who develop preeclampsia, experience more dramatic lipid changes compared with normotensive women ${ }^{7}$. Sharami et al ${ }^{7}$ reported deranged serum cholesterol levels in 58.5 $\%$, deranged LDL in $65.9 \%$, deranged HDL levels in $9.5 \%$ and deranged triglyceride levels in $58.5 \%$ women having preeclampsia.

Worldwide, preeclampsia and related-conditions are among the leading causes of maternal mortality particularly in developing countries as compared to developed nations ${ }^{8-14}$. So This study was done to ascertain derangement in serum lipid levels in these ladies with PE.

\section{MATERIAL AND METHODS}

A total of 135 women with preeclampsia (Both primigravida and multigravida) aged 20 - 40 years were included in our study. Patients with twin pregnancy, taking lipid lowering therapy were excluded from our study. Detailed history and physical examination was conducted. Five ml venous blood sample was drawn and sent to central pathology laboratory of Nishtar Hospital, Multan for serum lipid profile estimation. Data was analyzed by using SPSS Version 20. Mean and standard deviation was calculated for the numerical data like age of patients, BMI and serum lipid profile. Frequencies and percentages were tabulated for qualitative variables like dyslipidemia, diabetes, obesity, residential status, educational status, parity, family history of dyslipidemia and age groups.

\section{RESULTS}

Our study comprised of a total of 135 patients meeting inclusion criteria of our study. Mean gestational age of our study cases was $33.24 \pm 2.77$ weeks (with minimum gestational age was 21 weeks while maximum gestational age was 36 weeks). Our study results have indicated that majority of our patients i.e. $88(65.2 \%)$ had gestational age more than 30 weeks. Mean age of our study cases was $29.61 \pm 3.54$ years (with minimum age of our study cases was 22 years while maximum age was 37 years). Our study results have indicated that majority of our study cases i.e. $84(62.2 \%)$ were aged up to 30 years. Of these 135 study cases, $57(42.2 \%)$ belonged to rural areas and 78 $(57.8 \%)$ belonged to urban areas. Family history was positive in $41(30.4 \%)$ of our study cases. Diabetes was present in $25(18.5 \%)$ of our study cases. Mean parity was $2.59 \pm 1.72$ and $77(57.0 \%)$ had parity up to 3 . Mean body mass index of our study cases was $25.85 \pm 2.54 \mathrm{~kg} / \mathrm{m}^{2}$ and obesity was present in $31(23.0 \%)$ of our study cases. Of these 135 study cases, $104(77.0 \%)$ were illiterate while $31(23.0 \%)$ were literate. Of these 135 study cases, dyslipidemia was present in 73 (54.1\%). Mean Serum Cholesterol level was $223.45 \pm 47.21 \mathrm{mg} / \mathrm{dl}$ and it was deranged in $71(52.59 \%)$, mean serum LDL level was $147.15 \pm 31.25 \mathrm{mg} / \mathrm{dl}$ and it was deranged in 72 $(53.33 \%)$, mean serum triglyceride level was $154.21 \pm 15.29 \mathrm{mg} / \mathrm{dl}$ and it was deranged in $70(51.85 \%)$ of our study cases and mean HDL level was $52.42 \pm 8.53 \mathrm{mg} / \mathrm{dl}$ while it was deranged in 14 (10.37\%).

\section{DISCUSSION}

Pre-eclampsia is one of the most common causes of maternal and fetal morbidity and mortality. It is a systemic disease that affects about $5-7 \%$ of all pregnancies and is the most common, yet least understood disorder of pregnancy $^{8}$.

Mean age of our study cases was $29.61 \pm 3.54$ years (with minimum age of our study cases was 22 years while maximum age was 37 years). Our study results have indicated that majority of our study cases i.e. 84 (62.2\%) were aged up to 30 years. A study conducted in India by Kanagal et al ${ }^{8}$ reported $27.45 \pm 4.33$ years mean age of pre-eclamptic women which is close our study results. Vafaei et al ${ }^{15}$ reported similar results. A study conducted by Ugwuja et al ${ }^{16}$ from Nigeria reported $29.5 \pm 3.70$ years which is similar to that of our study results. Ephraim et al ${ }^{17}$ reproted $32.28 \pm 8.58$ years mean age in women with preeclampsia which is similar to that of our study results. Sirajwala et al ${ }^{18}$ reported $26.03 \pm 2.73$ years mean age which is close to our study results. 
Our study comprised of a total of 135 patients meeting inclusion criteria of our study. Mean gestational age of our study cases was $33.24 \pm 2.77$ weeks (with minimum gestational age was 21 weeks while maximum gestational age was 36 weeks). Our study results have indicated that majority of our patients i.e. $88(65.2 \%)$ had gestational age more than 30 weeks. A study conducted by Kanagal et al ${ }^{8}$ in India reported $36.9 \pm 0.9$ weeks mean gestational age in women with preeclampsia. These findings of Kanagal et al ${ }^{8}$ are similar to that of our study results. A study conducted by Ugwuja et al ${ }^{16}$ from Nigeria reported $21.4 \pm 3.22$ weeks mean gestational age which is quite less than that being reported in our study. Ephraim et al ${ }^{17}$ reported $30.72 \pm 2.84$ weeks mean gestational age which is in compliance with our study results. Sirajwala et al ${ }^{18}$ reported $34.48 \pm 3.52$ weeks mean gestational age which is similar to that of our study results.

Of these 135 study cases, 57 (42.2\%) belonged to rural areas and $78(57.8 \%)$ belonged to urban areas. Family history was positive in $41(30.4 \%)$ of our study cases. Diabetes was present in $25(18.5 \%)$ of our study cases. Mean parity was $2.59 \pm 1.72$ and $77(57.0 \%)$ had parity up to 3 . Ephraim et al ${ }^{17}$ reported similar results.

Mean body mass index of our study cases was $25.85 \pm 2.54 \mathrm{~kg} / \mathrm{m}^{2}$ and obesity was present in $31(23.0 \%)$ of our study cases. A study conducted by Kanagal et al from India ${ }^{8}$ reported $27.07 \pm 3.7 \mathrm{~kg} / \mathrm{m}^{2}$ which is similar to our findings. A study conducted by Ugwuja et al ${ }^{17}$ from Nigeria reported mean BMI $20.3 \pm 3.90 \mathrm{~kg} / \mathrm{m}^{2}$ which is less than that of our study findings. Ephraim et al ${ }^{17}$ reported $29.04 \pm 7.61 \mathrm{~kg} / \mathrm{m}^{2}$ which is higher than that of our study results.

Of these 135 study cases, dyslipidemia was present in 73 (54.1\%). Mean Serum Cholesterol level was $223.45 \pm$ $47.21 \mathrm{mg} / \mathrm{dl}$ and it was deranged in 71 (52.59\%), mean serum LDL level was $147.15 \pm 31.25 \mathrm{mg} / \mathrm{dl}$ and it was deranged in $72(53.33 \%)$, mean serum triglyceride level was $154.21 \pm 15.29 \mathrm{mg} / \mathrm{dl}$ and it was deranged in 70 $(51.85 \%)$ of our study cases and mean HDL level was $52.42 \pm 8.53 \mathrm{mg} / \mathrm{dl}$ while it was deranged in $14(10.37 \%)$. Sharami et $\mathrm{al}^{7}$ reported deranged serum cholesterol levels in $58.5 \%$, deranged LDL in $65.9 \%$, deranged HDL levels in $9.5 \%$ and deranged triglyceride levels in $58.5 \%$ women having preeclampsia. These findings are close to our study results.

\section{CONCLUSION}

Very high frequency of dyslipidemia was noted in our study in pre-eclamptic women. Dyslipidemia was significantly associated with gestational age, parity and diabetes. All the preeclamptic women should be screened for serum lipid levels and be managed accordingly to avoid future fetomaternal adverse outcomes.

\section{REFERENCES;}

1. Phalak P, Tilak M. Study of lipid profile in pre -eclampsia. Indian J Basic Applied Med Res. 2012;5(2):4059.

2. Jeyabalan A. Epidemiology of preeclampsia: impact of obesity. Nutr Rev. 2013;71:18-25.

3. Tabesh M, Salehi-Abargouei A, Tabesh M, Esmaillzadeh A. Maternal vitamin D status and risk of preeclampsia: a systematic review and meta-analysis. J Clin Endocrinol Metab. 2013;98(8):3165-73

4. Abalos E, Cuesta C, Carroli G, Qureshi Z, Widmer M, Vogel JP, et al. Pre-eclampsia, eclampsia and adverse maternal and perinatal outcomes: a secondary analysis of the World Health Organization Multicountry Survey on Maternal and Newborn Health. BJOG. 2014;121:14-24.

5. Hutcheon JA, Lisonkova S, Joseph KS. Epidemiology of pre-eclampsia and the other hypertensive disorders of pregnancy. Best Pract Res Clin Obstet Gynaecol. 2011;25(4):391-403.

6. Lo JO, Mission JF, Caughey AB. Hypertensive disease of pregnancy and maternal mortality. Curr Opin Obstet Gynecol. 2013;25(2):124-32.

7. Sharami SH, Tangestani A, Faraji R, Zahiri Z, Amiri A. Role of dyslipidemia in preeclamptic overweight pregnant women. Iran J Reprod Med. 2012;10(2):105-12.

8. Kanagal DV ${ }^{1}$, Rajesh $\mathrm{A}^{1}$, Rao $\mathrm{K}^{2}$, Devi $\mathrm{UH}^{3}$, Shetty $\mathrm{H}^{4}$, Kumari $\mathrm{S}^{5}$, et al. Levels of Serum Calcium and Magnesium in Pre-eclamptic and Normal Pregnancy: A Study from Coastal India. J Clin Diagn Res. 2014;8(7):OC01-4. doi: 10.7860/JCDR/2014/8872.4537.

9. Hutcheon JA, Lisonkova S, Joseph KS. Epidemiology of pre-eclampsia and the other hypertensive disorders of pregnancy. Best Pract Res Clin Obstet Gynaecol. 2011;25:391-403. 
10. von Dadelszen $\mathrm{P}^{1}$, Payne B, Li J, Ansermino JM, Broughton Pipkin F, Côté AM, et al. Prediction of adverse maternal outcomes in pre-eclampsia: development and validation of the fullPIERS model. Lancet. 2011;377:219-27.

11. Shand $\mathrm{AW}^{1}$, Nassar N, Von Dadelszen P, Innis SM, Green TJ. Maternal vitamin D status in pregnancy and adverse pregnancy outcomes in a group at high risk for pre-eclampsia. BJOG. 2010;117:1593-8.

12. Vadillo-Ortega $\mathrm{F}^{1}$, Perichart-Perera O, Espino S, Avila-Vergara MA, Ibarra I, Ahued R, et al. Effect of supplementation during pregnancy with L-arginine and antioxidant vitamins in medical food on preeclampsia in high risk population: randomised controlled trial. BMJ. 2011;342:d2901.

13. Kasawara $\mathrm{KT}^{1}$, do Nascimento SL, Costa ML, Surita FG, e Silva JL. Exercise and physical activity in the prevention of pre-eclampsia: systematic review. Acta Obstet Gynecol Scand. 2012;91:1147-57.

14. Hofmeyr GJ, Lawrie TA, Atallah AN, Duley L. Calcium supplementation during pregnancy for preventing hypertensive disorders and related problems. Cochrane Database Syst Rev. 2010;(8):CD001059.

15. Vafaei $\mathrm{H}^{1}$, Dalili $\mathrm{M}^{2}$, Hashemi $\mathrm{SA}^{2}$. Serum concentration of calcium, magnesium and zinc in normotensive versus preeclampsia pregnant women: A descriptive study in women of Kerman province of Iran. Iran $\mathbf{J}$ Reprod Med. 2015 Jan;13(1):23-6.

16. Ugwuja $\mathrm{EI}^{1}$, Famurewa $\mathrm{AC}^{2}$, Ikaraoha $\mathrm{CI}^{1}$. Comparison of Serum Calcium and Magnesium Between Preeclamptic and Normotensive Pregnant Nigerian Women in Abakaliki, Nigeria. Ann Med Health Sci Res. 2016 Jan-Feb;6(1):33-7.

17. Ephraim RK, Osakunor DN, Denkyira SW, Eshun H, Amoah S, Anto EO. Serum calcium and magnesium levels in women presenting with pre-eclampsia and pregnancy-induced hypertension: a case-control study in the Cape Coast metropolis, Ghana. BMC Pregnancy Childbirth. 2014 Nov 20;14:390. doi: 10.1186/s12884014-0390-2.

18. Sirajwala HB, Sharma D, Agravatt AM. A study of serum total calcium and uric acid levels in preeclampsia. Indian J Basic App Med Res. 2013;1(3):50-56. 